\title{
Detection of Circulating Melanoma Cells by a Two-marker Polymerase Chain Reaction Assay in Relation to Therapy
}

\author{
Ozlem Bitisik ${ }^{\dagger}$, Hakan Camlica ${ }^{\ddagger}$, Derya Duranyildiz ${ }^{\dagger}$, Faruk Tas ${ }^{\S}$, Sidika Kurul ${ }^{\ddagger}$ and Nejat Dalay ${ }^{\dagger *}$ \\ Istanbul University, Oncology Institute, \\ 'Departments of Basic Oncology, ${ }^{\ddagger}$ Preventive Oncology and ${ }^{\S}$ Clinical Oncology, Istanbul, Turkey
}

Received 6 September 2002, Accepted 14 October 2002

\begin{abstract}
Malignant melanoma is one of the most rapidly increasing cancer types, and patients with metastatic disease have a very poor prognosis. Detection of metastatic melanoma cells in circulation may aid the clinician in assessing tumor progression, metastatic potential, and response to therapy. Tyrosinase is a key enzyme in melanine biosynthesis. The gene is actively expressed in melanocytes and melanoma cells. Melan A is a differentiation antigen that is expressed in melanocytes. The presence of these molecules in blood is considered a marker for circulating melanoma cells. In this study, we analyzed the usefulness of this marker combination in evaluating the response to therapy in the blood of 30 patients with malignant melanoma. Circulating cells were detected by a reverse-transcriptasepolymerase-chain reaction. The tyrosinase expression was observed in $9(30 \%)$ patients and Melan A in $19(63.3 \%)$ patients before therapy. Following treatment, the tyrosinase mRNA was detected in only one patient, while Melan A transcripts were still present in 14 patients. We suggest that this molecular assay can identify circulating melanoma cells that express melanoma-associated antigens and may provide an early indication of therapy effectiveness.
\end{abstract}

Keywords: Chemotherapy, Malignant melanoma, Melan A, Tyrosinase

\section{Introduction}

Malignant melanoma is one of the fastest growing cancer forms with an annual increase of about 5\% (Mellado et al., 1996; Proebstle et al., 2000). Patients with metastatic disease have a very poor prognosis, with a 2-year survival rate of less

*To whom correspondence should be addressed. Tel: 90-212-5313100; Fax: 90-212-5348078/90-216-3387809 E-mail: ndalay@yahoo.com than 5\% (Evans and Manson, 1994). In general, malignant melanoma metastasizes via the lymphatics and blood. Unfortunately, the metastatic risk cannot be estimated early enough by routine diagnostic and imaging methods. The presence of melanoma cells in circulation seems to be positively correlated with the rapid progress of the disease (Shivers et al., 2001). Therefore, the detection of occult tumor cells in blood may permit a more accurate assessment of the prognosis and have important therapeutic implications (Foss et al., 1995).

Tyrosinase is a key enzyme in melanin biosynthesis. The gene codes for a 529 amino acid membrane-bound glycoprotein, and it is only actively expressed in melanocytes (Hoon et al., 1995; Lipton et al., 1997). The polymerase chain reaction-based detection of the tyrosinase messenger RNA in peripheral blood permits the detection of small numbers of circulating tumor cells. It has been reported that PCRpositivity during the early melanoma stages may indicate an increased risk for the development of hematogenous metastases (Mellado et al., 1996; Johansson et al., 2000).

Other genes, such as gp100 (Adema et al., 1994) or MUC18 and p97 (Curry et al., 1998), have also been reported to be expressed in cells of melanocytic origin. However, recent evidence suggests that these proteins are not specific to melanocytic cells, but can also be found in many different cell types (Brouwenstijn et al., 1997; Pickl et al., 1997; Curry et al., 1998). Therefore, these molecules are unsuitable for investigating melanoma cells in peripheral blood.

Another candidate as a marker is Melan A, the Melanoma Antigen that is recognized by the T-cells 1 (MART-1). The gene codes for a 118 amino acid melanocyte-lineage differentiation antigen that is only expressed in melanocytes, melanocytic cells, and in the retina (Coulie et al., 1994; Chen et al., 1996). The protein is recognized by melanoma-reactive CD8 cytotoxic T-cells (Zarour et al., 2000), and a peptide that is derived from the protein binds to the class I major histocompatibility complex HLA A2 molecule (Ouesnel et al., 2001). Most melanoma tumors and cell lines express this 
protein. However, its expression is not detected in other tissues and tumors (Goydos et al., 1998; Schittek et al., 1999).

The detection of circulating melanoma cells in peripheral blood may help in the initial diagnosis and staging by allowing the detection of subclinical metastases. It may also improve our ability to monitor the spreading of metastatic disease and provide a means to study the effects of systemic therapy on circulating tumor cells (Taback et al., 2001; Blaheta et al., 1998). Although multiple-marker analyses are more accurate than single-assay studies, combining different molecular parameters are rare, and the association between the detection of tumor cells and assessment of responsiveness to therapy and outcome has not been addressed adequately. In this study, we employed a sensitive two-marker RT-PCR assay to investigate the presence of tyrosinase and Melan A mRNAs in the peripheral blood of patients with malignant melanoma before and after therapy, in order to assess their utility in terms of treatment and prognosis.

\section{Materials and Methods}

Peripheral blood samples were collected from 30 patients (13 women and 17 men; mean age, $52.7 \pm 14$ ) with histologicallyconfirmed malignant melanoma with either localized or metastatic disease before and after treatment. The first blood sample was taken upon admission when all of the patients were still harboring the tumors. The final blood sample was collected two weeks after the completion of therapy. Blood was collected using EDTA as an anticoagulant, since heparin is known to inhibit both reverse transcriptase and Taq polymerase. Peripheral blood samples from 20 healthy donors were also investigated. To exclude variations in the amount of antigens, the blood samples from each patient were collected on two successive days at different times.

One patient had Stage II, 18 had Stage III, and 11 had Stage IV of the disease. Visceral metastases were present in 11 patients. Patients with the Stage III disease received Interferon $\left(9 \times 10^{6}\right.$ IU subcutaneously) 3 times weekly for one year. The Stage IV patients received systemic chemotherapy (DTIC $250 \mathrm{mg} / \mathrm{m}^{2}$ over 5 days at 28-day intervals, 6 cycles). The therapy consisted of 6 cycles of DTIC $200 \mathrm{mg} / \mathrm{m}^{2}+$ Cisplatin $25 \mathrm{mg} / \mathrm{m}^{2}$, for 3 days with 3 week intervals, when solid organ involvement was present.

The median follow-up interval after blood sampling was 17 months (range 11-31 months; mean, 17.9 \pm 5.4 months) for the patients.

Processing the blood with a density gradient before the RNA isolation resulted in a higher sensitivity than extracting RNA from whole blood (Jung et al., 1997; Schittek et al., 1999). Therefore, the mononuclear cell fractions were isolated by Ficoll-Histopaque (SIGMA Chemicals Inc., St. Louis, USA) density gradient centrifugation. Total cellular RNA was extracted from mononuclear cells using the Trizol Reagent (Gibco-BRL, USA). RNA quality was investigated electrophoretically on a $1 \%$ agarose gel. The integrity of the RNA samples was controlled by the consistent detection of $\beta$-actin mRNA to exclude mRNA degradation.

For the PCR analysis of the tyrosinase transcripts, two sets of primers were used from published sequences (Smith et al., 1991);

\section{HTYR1 : 5'-(TTGGCAGATTGTCTGTAGCC)-3' HTYR2 : 5' -(AGGCATTGTGCATGCTGCTT)-3' HTYR3 : 5' -(GTCTTTATGCAATGGAACGC)-3' HTYR4 : 5'-(GCTATCCCAGTAAGTGGACT)-3'.}

These primer pairs yielded products of $284 \mathrm{bp}$ and $207 \mathrm{bp}$, respectively.

Reverse transcription and PCR were performed using an Access RT-PCR kit (Promega, Madison, USA). One $\mu \mathrm{g}$ RNA was heated to $60^{\circ} \mathrm{C}$ for $5 \mathrm{~min}$, cooled rapidly on ice, and diluted to $50 \mu \mathrm{l}$ with a 1x PCR buffer, $1 \mathrm{mmol}$ of each dNTP, $1.6 \mathrm{mmol} \mathrm{MgSO}_{4}, 20 \mathrm{pmol}$ of each primer, $5 \mathrm{U}$ AMV-Reverse transcriptase, and $5 \mathrm{U}$ Tfl Polymerase. A cDNA synthesis was performed for $30 \mathrm{~min}$ at $48^{\circ} \mathrm{C}$. PCR was initiated for $5 \mathrm{~min}$ at $95^{\circ} \mathrm{C}$ for template denaturation, followed by 35 cycles of denaturation at $95^{\circ} \mathrm{C}$ for $65 \mathrm{~s}$, annealing at $55^{\circ} \mathrm{C}$ for $65 \mathrm{~s}$, and extension at $72^{\circ} \mathrm{C}$ for $65 \mathrm{~s}$. The PCR reaction was terminated by a $10-\mathrm{min}$ extension at $72^{\circ} \mathrm{C}$. For the second round, PCR $5 \mu \mathrm{l}$ of a $1: 100$ dilution of the first round PCR product was used in combination with $20 \mathrm{ng}$ of HTYR 3 and HTYR 4 primers in $50 \mu \mathrm{l}$ final volume. The cycling conditions were the same.

For the analysis of Melan A, the primers were as follows;

\section{MLA $1:$ ' '-CTGACCCTACAAGATGCCAAG-3' \\ MLA 2 : 5'-GATTAGTACTGCTAGCGGACC-3' \\ MLA 3 : 5'-ACTGCTCATCGGCTGTTGGT-3' \\ MLA 4 : 5'-TCAGCATGTCTCAGGTGTCT-3'.}

Three $\mu \mathrm{g}$ of RNA was suspended in a $50 \mu \mathrm{l}$ reaction mixture that contained $1 \mathrm{mmol}$ of each dNTP, $30 \mathrm{pmol}$ of each primer, $5 \mathrm{U}$ AMV Reverse transcriptase, $3.5 \mathrm{mmol} \mathrm{MgSO}_{4}, 0.2 \mathrm{M} \mathrm{DMSO}$, and $5 \mathrm{U}$ Tfl Polymerase. The PCR conditions were $60 \mathrm{sec}$ at $94^{\circ} \mathrm{C}$, $65 \mathrm{sec}$ at $54^{\circ} \mathrm{C}$, and $65 \mathrm{sec}$ at $72^{\circ} \mathrm{C}$ for 35 cycles. For reamplification, $1 \mu \mathrm{ICR}$ product was further processed in a second round of 35 cycles with nested primers (MLA 3 and MLA4) under the same conditions in the presence of $1.5 \mathrm{U}$ Taq polymerase. A product of $266 \mathrm{bp}$ was obtained following the second round of PCR.

The final products were electrophoresed on a $2 \%$ agarose gel, and evaluated using a gel documentation system (Vilber Lourmat, Marne-La-Vallee, France) after ethidium bromide staining. Positive RT-PCR results were repeated twice in order to confirm the results. The detection limit of our assay for both transcripts (1 melanoma cell in $10^{6}$ peripheral blood mononuclear cells) was in line with the studies in literature (Schittek et al., 1999; Proebstle et al. 2000; Taback et al. 2001).

Chi Square tests were used for the statistical calculations; a Kaplan-Meier analysis and logrank test were used for the survival analyses.

\section{Results}

We investigated the presence of tyrosinase and Melan A transcripts in 30 patients with malignant melanoma before and after therapy. The tyrosinase- and Melan A-specific bands in the patient samples are shown in Fig. 1 and 2. Tyrosinase transcripts were detected in 9 of 30 patients $(30 \%)$ with the metastatic disease before therapy. Five of 9 positive patients (28\%) had Stage III; 4 patients $(36 \%)$ had the Stage IV 


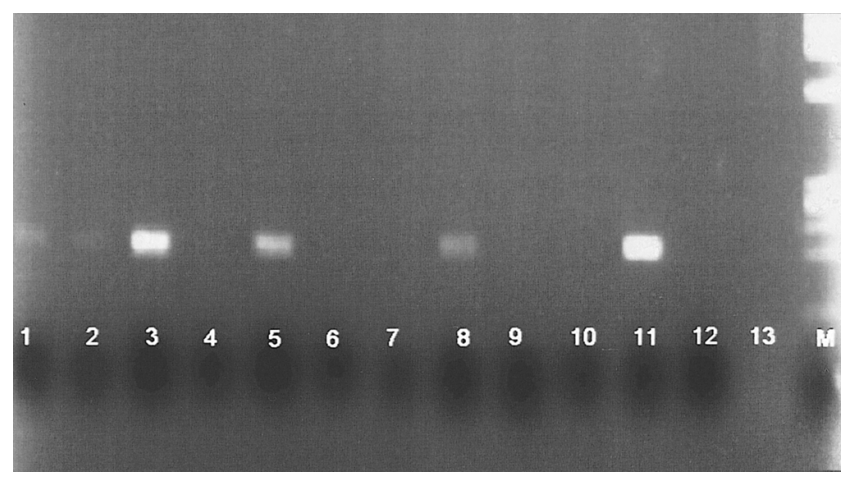

Fig. 1. RT-PCR products displaying the tyrosine-specific $207 \mathrm{bp}$ band in the positive samples. Lanes $1,2,3,5,8$, and 11; Tyrosinase-positive melanoma patients. Lanes 4, 6, and 7; Tyrosinase-negative patients. Lanes 9, 10, and 12; Healthy controls. Lane 13, Negative control. Lane M, Molecular weight marker.

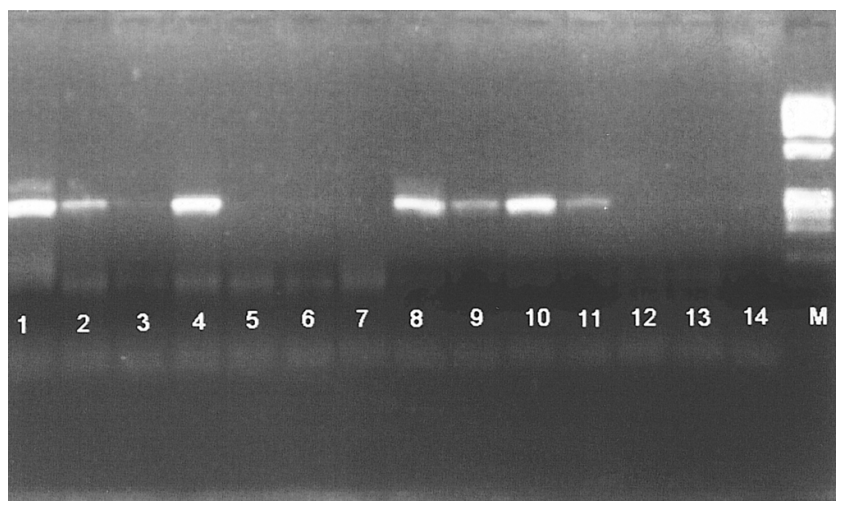

Fig. 2. Melan A-specific PCR transcripts. Lanes 1, 2, 4, 8, 9, 10, and 11; Melan A-positive patients. Lanes 3, 5, 6, and 7; Negative samples. Lanes 12 and 13, Healthy controls. Lane M; Molecular weight marker.

disease. The positivity rates for each group are given in Table 1. Following treatment, only one patient remained positive; while no transcript was detected in the remaining patients.

Upon admission, Melan A transcripts were observed in 19 (63.3\%) patients. All of the patients with the Stage IV disease were positive for Melan A transcripts. Among the patients at Stage III, 5 were positive for Melan A, 2 were positive for tyrosinase, and 3 patients were positive for both. Following therapy, Melan A was detected in 14 (46.6\%) patients. Of these, 8 patients had Stage III and 6 had Stage IV disease.

All of the healthy controls were negative for the tyrosinase and Melan A mRNAs. The difference between the patients and the control group was statistically significant, both for tyrosinase $(p=0.007)$ and Melan A $\left(p<0.001, \chi^{2}=22.22\right.$, $\mathrm{df}=1$ ). The specificities of tyrosinase and Melan A for the disease were high (100\%); however, the sensitivity of tyrosinase was considerably lower (30\%) when compared to Melan A $(63.3 \%)$. No statistical correlation between the
Table 1. Detection of tyrosinase and Melan-A transcripts by stage, and effect of therapy.

\begin{tabular}{ccccccc}
\hline & \multirow{2}{*}{ Stage } & $\mathrm{n}$ & \multicolumn{2}{c}{ Tyrosinase } & \multicolumn{2}{c}{ Melan A } \\
\cline { 4 - 7 } & & & $\mathrm{n}$ & $\%$ & $\mathrm{n}$ & $\%$ \\
\hline Before & III & 18 & 5 & 28 & 8 & 44 \\
Therapy & IV & 11 & 4 & 36 & 11 & 100 \\
After & III & 14 & - & - & 8 & 57 \\
Therapy & IV & 6 & 1 & 9 & 6 & 100 \\
\hline
\end{tabular}

presence of PCR products and age or sex was observed. During the entire period four patients were found negative on both parameters. Remarkably, in the negatively-tested group, 2 patients relapsed and were lost during the study.

Following treatment, tyrosinase mRNA was observed in only one patient $(9 \%)$. This reflects the effect of systemic therapy on circulating tumor cells. On the other hand, Melan A transcripts were still detectable in 14 (70\%) patients after therapy. During the follow-up period of the disease, 9 patients ( 5 patients with the Stage IV disease and 4 patients with the Stage III disease) were lost by disease-related deaths. Of these, two patients were positive for Melan A on admission; one patient was positive for both markers. All of these patients had the Stage IV disease. However, this observation failed to achieve a significant association. Among the patients who were found positive for at least one of the markers on admission, 8 patients are still without relapse, while the remaining patients all had recurrences. Remarkably, among the patients in remission, three were found positive for tyrosinase on admission and turned negative following therapy. However, of the six patients who were positive for Melan A initially, only one turned negative.

The survival analysis revealed no association with PCR positivity for both transcripts.

\section{Discussion}

Routine histologic examinations are inadequate for accurately assessing the diseases spread and monitoring the progression and micrometastatic disease (Goydos et al., 1998). A possible alternative is the use of RT-PCR to detect tumor-specific mRNA in circulation. Since subclinical metastasis may remain dormant for many years, monitoring a patients blood for circulating tumor cells may be advantageous for detecting tumor progression before clinically-evident metastases are detected. This information may be useful in identifying patients who may benefit from more intense therapies, and provide an opportunity for therapeutic intervention at an earlier stage. However, the assessment of single markers has limitations in sensitivity and specificity, based on the heterogeneity of the marker expression among tumors (Kulik et al., 2001). Furthermore, although specific molecular techniques have been utilized for diagnostic purposes, the 
correlation between molecular detection of circulating tumor cells and the response to therapy has not been addressed satisfactorily.

In this study, our goal was to improve the sensitivity to detect micrometastases in the circulation of melanoma patients by the simultaneous analysis of tyrosinase and Melan A transcripts. Also, we investigated to see if these markers are predictive of the therapeutic response in a clinical setting.

In our study, tyrosinase transcripts were observed in $30 \%$ of the patients. The positivity rate for tyrosinase transcripts is in accordance with literature (Foss et al., 1995; Kunter et al., 1996; Pittman et al., 1996; Jung et al., 1997; Proebstle et al., 2000), but higher than two reports in which only a small fraction of the patients were found to have detectable numbers of cells in blood with this technique (Hoon et al., 1995; Johansson et al., 2000). However, considerable variations in the rate of detection have also been noted (Hoon et al., 1995; Jung et al., 1997). This may indicate that although tyrosinase transcripts are commonly found in patients with disseminated disease, they may also be absent in patients during the earlier stages of the disease (Berking et al., 1999).

All of the patients that were positive for tyrosinase mRNA in our study had Stage III and IV of the disease. This agrees with previous studies (Brossart et al., 1995; O'Connell et al., 1998), which reported a high sensitivity for patients with stage IV melanoma. A correlation between the presence of tyrosinase mRNA in blood and stage of the disease was reported in several studies (Mellado et al., 1996; Forthmann et al., 1998; Proebstle et al., 2000).

Following chemotherapy, tyrosinase mRNA was found in only one of the patients. This probably reflects the effects of systemic therapy on circulating tumor cells. The continued presence of circulating cells after treatment is likely to be associated with a poor outcome. Our observations agree with reports that tyrosinase alone may not always provide a useful marker in detecting circulating melanoma cells (Hoon et al., 1995; Hasselmann et al., 2001). This finding supports the view that the use of more than one marker is required in order to verify the presence of occult melanoma cells in peripheral blood (Hoon et al., 1995; Schittek et al., 1999a; Schittek et al., 1999b).

Therefore, another melanocytic-lineage marker, Melan A, was included. Melan A is specifically expressed in melanocytes, melanoma cells, and in the retina (Coulie et al., 1994; Chen et al., 1996). We observed the expression of the Melan A transcript in $63 \%$ of the patients. This ratio is consistent with an earlier report (Curry et al., 1999), as well as the hypothesis that most melanoma tumors and cell lines express this gene (Schittek et al., 1999). In agreement with previous reports (Kulik et al., 2001; Taback et al., 2001), the frequency of melanoma cell detection in a patients blood was higher in our study when the two-marker assay was used. However, Melan A transcripts were still detectable in $43 \%$ of the patients following chemotherapy. This may indicate that Melan A may be more specific to the disease and not completely eradicated by chemotherapy. It has been reported that positive tyrosinase results are less frequently observed in the treated-Stage IV patients than in the untreated patients (De Vries et al., 1999). Alternatively, it may also be due to the fact that the down-regulation of melanin synthesis is more easily achieved by treatment, while the antigen-expressing pathways may still remain functional.

Although the investigation of tyrosinase seems to better reflect the effect of systemic therapy, this may be due to the low sensitivity of tyrosinase. Reports, which suggest that tyrosinase transcripts are commonly found in disseminated disease and may be absent in earlier stages, support this notion (Glaser et al., 1997; Schittek et al., 1999). Although it was reported that circulating-tumor cells can be detected in melanoma patients without clinical evidence of the disease (Brossart et al., 1994), this was not the case in our study group. However, our findings are in agreement with a more recent report (Kunter et al., 1996). We observed no association between the presence of transcripts and survival.

Our study supports the view that tyrosinase-negative samples may contain Melan A transcripts (Schittek et al., 1999), and that the simultaneous detection of two independent markers may increase sensitivity that enables the detection of micrometastases, particularly in patients in whom the expression of one marker is down-regulated. This finding is consistent with other studies (Hoon et al., 1995; Kulik et al., 2001; Taback et al., 2001). Since detection limits are roughly the same for both transcripts, the higher detection rate for Melan A may be associated with the characteristics of the tumor cell.

The specificity of tyrosinase and the Melan A gene expression makes this approach ideal for detecting melanoma cells in blood. We conclude that this molecular assay can provide information on the persistence of metastatic melanoma cells, and may assist in monitoring the efficacy of treatment. Further studies are needed to better assess the significance of this test in the evaluation of prognosis and early detection of relapse.

Acknowledgments This study was supported by the Istanbul University Research Fund (Project Nr. O-III-78/ 08122000).

\section{References}

Adema, G. J., de Boer, A. J., Vogel A. M., Loenen, W. A. and Figdor, C. G. (1994) Molecular characterization of the melanocyte lineage-specific antigen gp 100. J. Biol. Chem. 269, 20126-20133.

Berking, C., Schlüpen, E. M., Schrader, A., Atzpodien, J. and Vokenandt, M. (1999) Tumor markers in peripheral blood of patients with malignant melanoma: Multimarker RT-PCR versus a luminoimmunometric assay for S-100. Arch. Dermatol. 291, 479-484.

Blaheta, H. J., Schittek, B., Breuninger, H., Maczey, E., Kroeber, S., Sotlar, K., Esswanger, U., Thelen, M. H., Rassner, G., 
Bultmann, B. and Garbe, C. (1998) Lymph node micrometastases of cutaneous melanoma: Increased sensitivity of molecular diagnosis in comparison to immunohistochemistry. Int. J. Cancer. 79, 318-323.

Brossart, P., Keilholz, U., Scheibenbogen, C., Mohler, T., Willhauck, M. and Hunstein, W. (1994) Detection of residual tumor cells in patients with malignant melanoma responding to immunotherapy. J. Immunother. 15, 38-41.

Brossart, P., Schmier, J. W., Kruger, S., Willhauck, M., Scheibenbogen, C., Mohler, T. and Keilholz, U. (1995) A polymerase chain reaction-based semiquantitative assessment of malignant melanoma cells in peripheral blood. Cancer Res. 55, 4065-4068.

Brouwenstijn, N., Slager, E. H., Bakker, A. B. H., Schreurs, M. W., Van der Spek, C. W., Adema, G. J., Schrier, P. I. and Figdor, C. G. (1997) Transcription of the gene encoding melanoma-associated antigen gp100 in tissues and cell lines other than those of the melanocytic lineage. Br. J. Cancer. 76, 1562-1566.

Chen, Y. T., Stockert, E., Jungbluth, A., Tsang, S., Coplan, K. A., Scanlan, M. J. and Old, L. J. (1996) Serological analysis of Melan-A (MART-1), a melanocyte-specific protein homogeneously expressed in human melanomas. Proc. Natl. Acad. Sci. USA 93, 5915-5919.

Coulie, P. G., Brichard, V., van Pel, A., Wolfel, T., Schneider, J., Traversari, C., Mattei, S., De Plaen, E., Lurquin, C. and Szikora, J. P. (1994) A new gene coding for a differentiation antigen recognized by autologous cytolytic $\mathrm{T}$ lymphocytes on HLA-A2 melanomas. J. Exp. Med. 180, 35-42.

Curry, B. J., Myers, K. and Hersey, P. (1998) Polymerase chain reaction detection of melanoma cells in the circulation: Relation to clinical stage, surgical treatment and recurrence from melanoma. J. Clin. Oncol. 16, 1760-1769.

Curry, B. J., Myers, K. and Hersey, P. (1999) MART-1 is expressed less frequently on circulating melanoma cells in patients who develop distant compared with locoregional metastases. J. Clin. Oncol. 17, 2562-2571.

De Vries, T. J., Fourkour, A., Punt, C. J. A., van de Locht, L. T., Wobbes, T., van den Bosch, S., de Rooij, M. J., Mensink, E. J., Ruiter, D. J. and van Muijgen, G. N. (1999) Reproducibility of detection of tyrosinase and MART-1 transcripts in the peripheral blood of melanoma patients: a quality control study using real-time quantitative RT-PCR. Br. J. Cancer 80, 883891.

Evans, G. R. D. and Manson, P. N. (1994) Review and current perspectives of cutaneous malignant melanoma. J. Am. College Surg. 178, 524-540.

Farthmann, B., Eberle, J., Krasagakis, K., Gstottner, M., Wang, N., Bisson, S. and Orfanos, C. E. (1998) RT-PCR for tyrosinasemRNA-positive cells in peripheral blood: evaluation strategy and correlation with known prognostic markers in melanoma patients. J. Invest. Dermatol. 110, 263-267.

Foss, A. J., Guille, M. J., Occleston, N. L., Hykin, P. G., Hungerford, J. L. and Lightman, S. (1995) The detection of melanoma cells in peripheral blood by reverse transcriptionpolymerase chain reaction. Br. J. Cancer 72, 155-159.

Glaser, R., Rass, K., Seiter, S., Hauschild, A., Christophers, E., and Tilgen, W. (1997) Detection of circulating melanoma cells by specific amplification of tyrosinase complementary DNA is not a reliable tumor marker in melanoma patients: a clinical two-center study. J. Clin. Oncol. 15, 2818-2825.

Goydos, J. S., Ravikumar, T. S., Germino, F. J., Yudd, A. and Bancila, E. (1998) Minimally invasive staging of patients with melanoma: Sentinel lympadenectomy and detection of the melanoma-specific proteins MART-1 and tyrosinase by reverse transcriptase polymerase chain reaction. J. Am. Coll. Surg. 187, 182-190.

Hasselmann, D. O., Rappl, G., Rossler, M., Ugurel, S., Tilgen, W. and Reinhold, U. (2001) Detection of tumor-associated circulating mRNA in serum, plasma and blood cells from patients with disseminated malignant melanoma. Oncol. Rep. 8, 115-118.

Hoon, D., Wang, Y., Dale, P. S., Conrad, A. J., Schmid, P., Garrison, D., Kuo, C., Foshag, L. J., Nizze, A. J. and Morton, D. L. (1995) Detection of occult melanoma cells in blood with a multiple-marker polymerase chain reaction assay. J. Clin. Oncol. 13, 2109-2116.

Johansson, M., Pisa, E. K., Törmanen, V., Arstrand, K. and Kagedal, B. (2000) Quantitative analysis of tyrosinase transcripts in blood. Clin. Chem. 46, 921-927.

Jung, A. F., Buzaid, A. C., Ross, M. I., Woods, K. V., Lee, J. J., Albitar, M. and Grimm, E. A. (1997) Evaluation of tyrosinase mRNA as a tumor marker in the blood of melanoma patients. J. Clin. Oncol. 5, 2826-2831.

Kulik, J., Nowecki, Z. I., Rutkowski, P., Ruka, W., Rochowska, M., Skurzak, H. and Siedlecki, J. A. (2001) Detection of circulating melanoma cells in peripheral blood by a two marker RT-PCR assay. Melanoma Res. 11, 65-73.

Kunter, U., Buer, J., Probst, M., Duensing, S., Dallmann, I., Grosse, J., Krichner, H., Schluepen, E. M., Volkenandt, M., Ganser, A. and Atzpodien, J. (1996) Peripheral blood tyrosinase messenger RNA detection and survival in malignant melanoma. J. Natl. Cancer Inst. 88, 590-594.

Lipton, A., Curley, E., Leitzel, K., Harvey, H. A., Chen, L. and Bystryn, J. C. (1997) Detection of circulating melanoma cells in patients using RT-PCR. Proc. Annu. Meet. Am. Soc. Clin. Oncol. 16, A1821.

Mellado, B., Colomer, D., Castel, T., Munoz, M., Carballo, E., Galan, M., Mascaro, J. M., Vives-Corrons, J. L., Grau, J. J. and Estape, J. (1996) Detection of circulating cells by reverse transcriptase polymerase chain reaction in malignant melanoma: Association with clinical stage and prognosis. J. Clin. Oncol. 14, 2091-2097.

O'Connell, D. C., Juhasz, A., Kuo, C., Reeder, D. J. and Hoon, D. S. (1998) Detection of tyrosinase mRNA in melanoma by reverse transcription-PCR and electrochemiluminescence. Clin. Chem. 44, 1161-1169.

Pickl, W. E., Majdic, O., Fischer, G. F., Petzelbauer, P., Fae, I., Waclavicek, M., Stockl, J., Scheinecker, C., Vidicki, T., Aschauer, H., Johnson, J. P. and Knapp, W. (1997) MUC18/ MCAM (CD146), an activation antigen of human $\mathrm{T}$ lymphocytes. J. Immunol. 158, 2107-2115.

Pittman, K., Burchill, S., Smith, B., Southgate, J., Joffe, J., Gore, M., and Selby, P. (1996) Reverse transcriptase polymerase chain reaction for expression of tyrosinase to identify malignant melanoma cells in peripheral blood. Annal. Oncol. 7, 197-201.

Proebstle, T. M., Jiang, W., Högel, J., Keilholz, U., Weber, L. and Voit, C. (2000) Correlation of positive RT-PCR for tyrosinase in peripheral blood of malignant melanoma patients with clinical stage, survival and other risk factors. Br. J. Cancer 82, 
118-123.

Quesnel, A., Zerbib, A., Connan, F., Guillet, J. G., Briand, J. P., and Choppin, J. (2001) Synthesis and antigenic properties of reduced peptide bond analogues of an immunodominant epitope of the melanoma MART-1 protein. J. Pept. Sci. 7, 157165.

Schittek, B., Blaheta, H. J., Flörchinger, G., Sauer, B. and Garbe, C. (1999a) Increased sensitivity for the detection of malignant melanoma cells in peripheral blood using an improved protocol for reverse transcription-polymerase chain reaction. $B r . J$. Dermatol. 141, 37-43.

Schittek, B., Bodingbauer, Y., Ellwanger, U., Blaheta, H. J. and Garbe, C. (1999b) Amplification of Melan A messenger RNA in addition to tyrosinase increases sensitivity of melanoma cell detection in peripheral blood and is associated with the clinical stage and prognosis of malignant melanoma. $\mathrm{Br}$. J. Dermatol. 141, 30-36.

Shivers, S. C., Li, W., Lin, J., Stall, A., Stafford, M., Messina, J.,
Glass, L. F. and Reintgen, D. S. (2001) The clinical relevance of molecular staging for melanoma. Recent Results Cancer Res. 158, 187-199.

Smith, B., Selby, P., Southgate, J., Pittman, K., Bradley, C. and Blair, G. E. (1991) Detection of melanoma cells in peripheral blood by means of reverse transcriptase and polymerase chain reaction. Lancet 338, 1227-1229.

Taback, B., Morton, D. L., ODay, S. J., Nguyen, D. H., Nakayama, T. and Hoon, D. S. (2001) The clinical utility of multimarker RT-PCR in the detection of occult metastasis in patients with melanoma. Recent Results Cancer Res. 158, 7892.

Zarour, H. M., Kirkwood, J. M., Kierstead, L. S., Herr, W., Brusic, V., Slingluff, C. L., Sidney, J., Sette, A. and Storkus, W. J. (2000) Melan-A/MART-1 represents an immunogenic HLA-DR4-restricted epitope recognized by melanoma-reactive CD4 ${ }^{+}$T cells. Proc. Natl. Acad. Sci. USA 97, 400-405. 